${ }^{1}$ Department of Morphology, Genetics, Orthodontic and Pediatric Dentistry, Araraquara School of Dentistry, São Paulo State University (UNESP), Araraquara, SP, Brazil

${ }^{2}$ CES University, Faculty of Dentistry, Medelin, Colômbia.

Corresponding author: Vinicius Krieger Costa Nogueira Department of Morphology, Genetics, Orthodontic and Pediatric Dentistry, Araraquara School of Dentistry, (UNESP)

Rua Humaitá, 1680, 14801-903

Araraquara, SP, Brazil.

Fone/Fax: +55 (16) 3301-6334

E-mail: vinicius.nogueira@unesp.br

Editor: Dr Altair A. Del Bel Cury

Received: September 8, 2020

Accepted: March 10, 2021

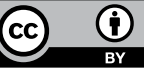

\section{Impact of the undergraduate clinical teaching-learning process on caries detection and treatment decision-making}

\author{
Silas Alves Costa ${ }^{1} \mathbb{D}$, Vinicius Krieger Costa Nogueira ${ }^{1, *}$, \\ Diego Girotto Bussanelli1(D, Manuel Restrepo이, \\ Alfonso Escobar ${ }^{2} \mathbb{B}$, Rita de Cássia Loiola Cordeiro ${ }^{1}$ (1)
}

Aim: The aim of this study was to evaluate caries diagnosis and treatment decisions made by undergraduate dental students based on ICDAS or Nyvad criteria. Methods: Twelve students analyzed 90 digital photographs of permanent teeth at different clinical stages of carious lesion development and chose among different treatments in three different assessments: when there was no knowledge of the criteria (described as "No knowledge (N)"; when there was theoretical knowledge of the criteria (described as "Theoretical knowledge (T)" and when there was theoretical knowledge, clinical experience about dental caries and the criteria (described as "Theoretical and clinical knowledge (TC)". For "T" and "TC" the students were randomized into two experimental groups - ICDAS or Nyvad (experimental units: 6 students/group) The reference standard was established cooperatively by two experienced researchers. Criteria performance was evaluated by sensitivity, specificity, AUC, and Kappa statistics. Treatment decision was described in percentage by contingency tables and Spearman's correlation with the reference standard. Results: The first assessment demonstrated a high percentage of operative treatment even for initial enamel lesions based on ICDAS criteria and treatment was proposed for both active and inactive lesions, according to the Nyvad criteria. In the second assessment, the students continued recommending treatments for initial or inactive lesions, but less frequently. In the third assessment, treatment decisions presented greater cohesion in relation to the assigned classification criterion. The criteria presented no differences between them in terms of diagnostic in the third assessment. Conclusion: Clinical experience may improve caries detection and treatment decisions with the use of ICDAS and Nyvad criteria.

Keywords: Dental caries. Education. Diagnosis. 


\section{Introduction}

Decision-making for the establishment of appropriate clinical treatment is a complex process that presents as a task of solving a particular problem ${ }^{1}$. Most dentists examine their patients with the aim of determining a treatment plan without giving careful attention to establishing a correct diagnosis. Thus, important information may be lost and some treatment options may be underestimated ${ }^{2,3}$.

Many factors may influence undergraduate students' clinical management decisions during their education, such as theoretical knowledge and clinical training. By analyzing the curriculum content of European dental schools, Bottenberg et al. ${ }^{4}$ found that the teaching content of cariology was unequal among the universities and was fragmented into many other subjects. Nonetheless, knowledge of cariology is fundamental for the construction of critical thinking, both during undergraduate studies and in one's career ${ }^{5,6}$. In addition, Ferreira-Nóbilo et al. ${ }^{7}$ observed that although most Brazilian schools contemplating the theme in their disciplines, the little emphasis on specific clinical practice may be contributing to the inequality distribution of the disease in the country.

Visual inspection is a method commonly taught at dental schools for caries detection and allows having a good performance even if it is not associated with other methods ${ }^{8,9}$. In order to facilitate the detection of carious lesions, reduce subjective decision-making, and improve the standardization of studies and epidemiological surveys, different indices with well-defined criteria have been developed ${ }^{10,11}$. The International Caries Detection and Assessment System (ICDAS) classifies lesions according to signs such as spots, pigmentations, cavities, and the association among these signs can suggest the extent of the carious lesion, with application of scores (1-6) for staging of the lesions ${ }^{10,12}$. ICDAS has shown good validity and reproducibility in determining the presence or absence of caries in both primary and permanent teeth. On the other hand, the criteria developed by Nyvad are used as a scoring system to identify the physical traits for caries activity based on visual-tactile aspects, detecting and distinguishing clinical signs, such as translucency or opacity, surface texture, and plaque stagnation area $^{13}$.

Theoretical knowledge and expertise seem to have some importance for the application of criteria for the detection of signs that indicate the presence or absence of carious lesions and, consequently, for the decisions about the treatment to be offered to the patient ${ }^{14-16}$. According to a recent systematic review ${ }^{8}$, undergraduate students demonstrate good performance in caries detection and staging using visual inspection, but their performance in the assessment of caries activity still needs improvement. Bussaneli et al. ${ }^{16}$ pointed out poor clinical experience as a possible influence on the choices of undergraduate students for more invasive dental caries treatments. The few studies on this subject ${ }^{1,16-19}$ assessed a single moment of the students' experience during their undergraduate program, mostly in their senior year.

Despite the considerable number of studies on the performance of visual criteria, the relationship between students' experience, visual criteria, and treatment deci- 
sions is still unclear. Therefore, the aim of this study was to evaluate dental caries diagnosis and treatment decisions made by undergraduate students at three different assessments: when there is no knowledge of the criteria (described as "No knowledge $(\mathrm{N})$ "; when there is theoretical knowledge of the criteria (described as "Theoretical knowledge $(T)$ " and when there is theoretical knowledge, clinical experience about dental caries and the criteria (described as "Theoretical and clinical knowledge (TC)".

\section{MATERIALS AND METHODS}

This study is part of a macro project, and its data have been partially published by Nogueira et al. ${ }^{14}$ The data obtained and analyzed here are unique; however, the methodology is similar to that described in that other article.

\section{Study participants}

After approval of the study protocol by the Research Ethics Committee of the Araraquara Dental School (FOAr), Araraquara, Brazil (process 701/14), 75 undergraduate students in the second year/fourth semester were directly invited to participate. Twelve students (response rate: 16\%) agreed to participate. This means that the sample was selected by convenience sampling. They were all in the same academic semester, with the same level of knowledge and experience in all phases of this study. In the second year, students take basic courses in health sciences. This means they are taught about dental caries development; however, at that stage, they have not learned about the clinical specificities of carious lesions, have had no previous experience with ICDAS or Nyvad criteria, and have not yet had clinical experience. We emphasize that this Dentistry course lasts five years and does not have a specific discipline of Cariology. The content on this topic is covered in the disciplines of Histology, Restorative Dentistry and Pediatric Dentistry, without minimum workload.

\section{Study design}

Ninety digital photographs of permanent teeth at different clinical stages of carious lesion development were used. The photographs were taken during the selection of patients by the researchers in charge of establishing the reference standard. The photographed tooth should allow direct visualization of the carious lesion, regardless of whether the lesion was located on the proximal, occlusal, or buccolingual surface. The photographs were assessed at the Informatics Teaching Laboratory of FOAr using a 21.5-inch LED screen with 1920×1080 pixel resolution and the site to be analyzed was indicated precisely by an arrow. The design of the methodology described below is illustrated in our study flow-chart (Fig. 1).

Initially, the undergraduate students analyzed the photographs by looking at the carious lesion site and assigning a treatment decision score according to their own theoretical knowledge about dental caries, without any training or calibration about the criteria. At this time, the students have not been evaluated about the diagnosis using ICDAS and Nyvad criteria because this assignment is only possible after some knowledge about the codifications, for this reason this assessment 


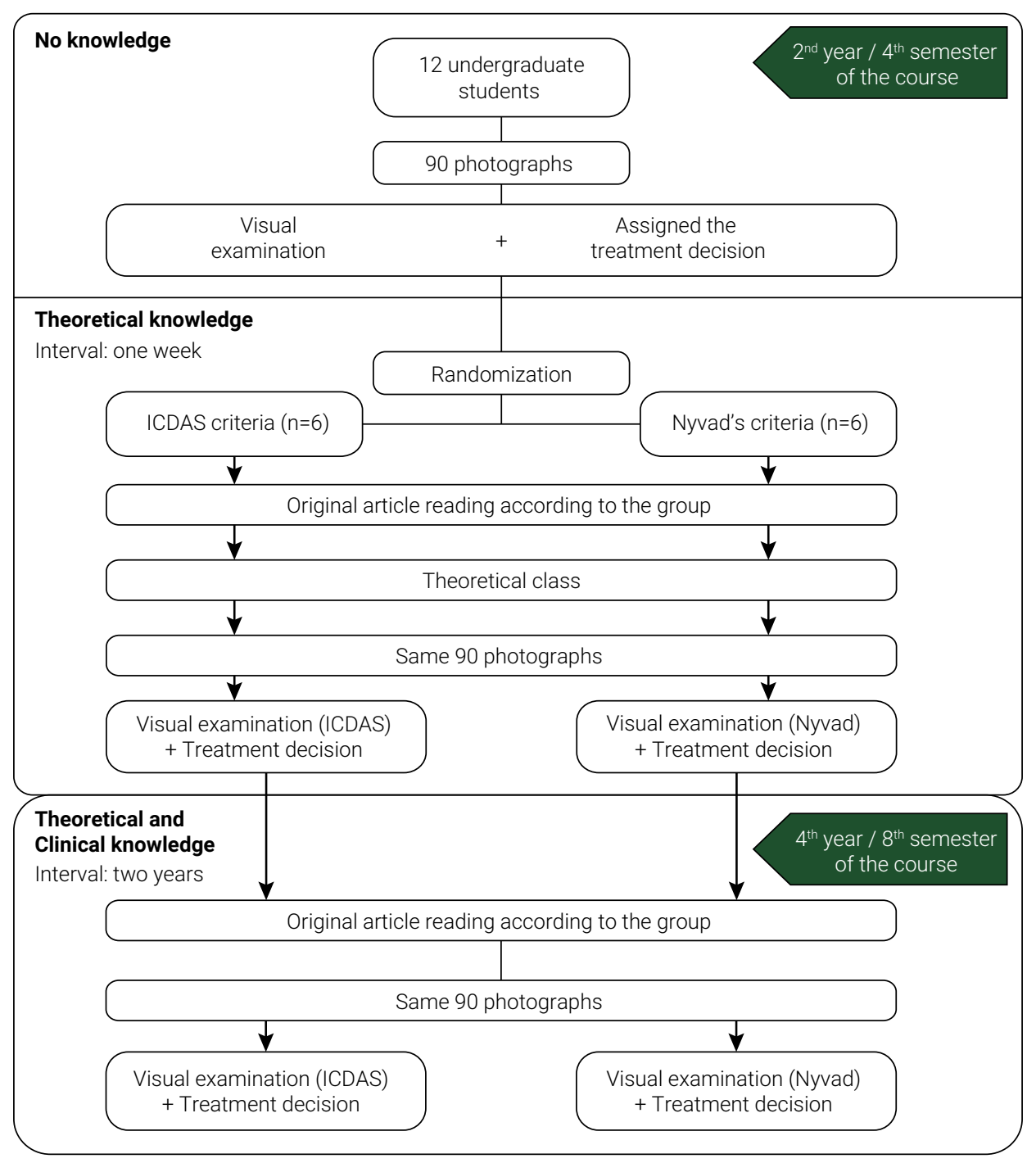

Figure 1. Study flowchart

was described as "No knowledge $(\mathrm{N})$ ". For treatment decisions, students should assign a score among the options: (0) no treatment; (1) non-operative treatment: oral hygiene instruction and application of 5\% fluoride varnish; (2) operative treatment: sealant or restoration with composite resin or restoration with conventional glass ionomer cement.

After this first assessment, the students were then randomized through an online randomization tool (http://www.random.org) into two experimental groups - ICDAS or Nyvad (experimental units: 6 students/group) criteria - and received the original article that described each criterion ${ }^{8,9}$. After reading the article, each group attended an expository lesson about the etiology, pathogenesis, and diagnosis of dental caries based on the assigned criteria (either ICDAS or Nyvad) and treatment decisions. 
In the following week, the students performed the second assessment of the same photographs. The difference was that, before choosing the treatment score, students classified and scored the selected sites according to the ICDAS or Nyvad criteria, depending on the group to which they belonged (Fig. 2). The carious lesion classification criteria were provided on a printout. Here, we reinforce that treatment decisions

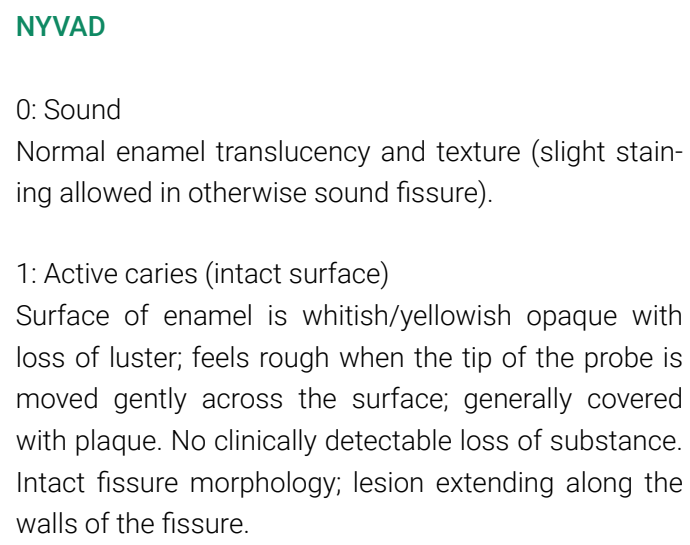
may be shiny and feels hard and smooth when the tip of the probe is moved gently across the surface. No clinically detectable loss of substance. Intact fissure morphology; lesion extending along the walls of the fissure.

\section{5: Inactive caries (surface discontinuity)}

Same criteria as score 4. Localized surface defect (microcavity) in enamel only. No undermined enamel or softened floor detectable with the explorer.

\section{6: Inactive caries (cavity)}

Enamel/dentine cavity easily visible with the naked eye; surface of the cavity feels shiny and feels hard on gentle probing. No pulpal involvement.

\section{ICDAS}

0 : No or slight change in enamel translucency after prolonged air drying (5 s).

1: First visual change in enamel (seen only after prolonged air drying or restricted to within the confines of a pit or fissure).

2: Distinct visual changes in enamel.

3: Localized enamel breakdown in opaque or discolored enamel (without visual signs of dentinal involvement).

4: Underlying dark shadow from dentine.

5: Distinct cavity with visible dentine (involving less than half of the surface).

6: Extensive distinct cavity with visible dentine (involving more than half of the surface).

Figure 2. Criteria used in the visual assessment. 
were followed exclusively based on their theoretical knowledge, however, taken after the specific criterion training. For this reason, this assessment was described as "Theoretical knowledge $(T)^{\prime \prime}$.

The third assessment was carried out two years after the first one using the same photographs. The undergraduate students were now enrolled in the fourth year/eighth semester of the course. The original articles were handed out again and a new analysis was performed one week after the students read them. In this assessment, the students scored the selected sites according to the criterion belonged and also with a treatment score. At this moment, the treatment decisions were based on their theoretical knowledge enhanced with clinical experience about dental caries. For this reason, this assessment was described as "Theoretical and clinical knowledge (TC)".

This methodology aimed to evaluate the different factors related to this study: the purely theoretical knowledge about dental caries; the theoretical knowledge about dental caries after specific training for each criterion; and knowledge about dental caries when theoretical and clinical practice are combined. For this, we analyze these factors through the performance of the students based on their treatment decisions supported or not by the criteria.

\section{Reference standard}

The reference standard used for encoding criteria and for treatment decisions was established by two experienced researchers. Initially, these researchers cooperatively analyzed 50 photographs and discussed the classification of the lesions according to the different criteria and possible treatments. After one week, they independently performed a new assessment and the reproducibility analyses resulted in good interrater reliability (Kappa ICDAS: 0.84; Kappa Nyvad: 0.82; and Kappa Treatment decisions: 0.87).

After the calibration process, the same researchers were responsible for selecting the teeth that were really part of the present study. This occurred in the clinical assessments during the selection of patients in the Department of Clinical Pediatrics of FOAr during the obligatory inclusion check for regular treatment. The included teeth were classified according to the ICDAS and Nyvad criteria, to the need for treatment and photographed. Treatment decisions were chosen according to the depth/extent of the lesion associated with its activity. All different caries scores were included, but the ratio it was not necessary the same.

\section{Statistical analysis}

MedCalc software (Mariakerke - Be. Version 9.3 for Windows) was used for the statistical analysis. As response variables, it was adopted that both treatment and criteria scores represent the dependent variables, while the different assessments represent the independent variables.

Sensitivity, specificity, and area under ROC curve (AUC) determine different cutoff points according to the presence of cavitation (ICDAS) and in relation to disease activity (Nyvad). Cutoff points were established according to ICDAS for sound teeth and enamel-dentin lesions (considering ICDAS scores from 4 to 6 as disease) and accord- 
ing to Nyvad criteria for sound teeth, inactive lesions, and active lesions (considering Nyvad scores from 1 to 3 as disease). The groups were intra and inter-compared by means of a McNemar's test and the significance level was set at $P<0.05$. Kappa statistics (Cohen's Kappa) were used to evaluate the diagnostic criteria performance in the second and third assessments of each group compared to the gold standard, represented by an interrater.

For treatment decisions, the percentage distribution within ICDAS and Nyvad score criteria was described in contingency tables and the correlation with the reference standard was determined using Spearman's correlation coefficient.

\section{RESULTS}

According to the reference standard established in the clinical evaluations, the sample consisted of photographs of 21 (23\%) sound teeth, 30 (34\%) teeth with enamel lesions, and $39(43 \%)$ teeth with dentin lesions. Considering the activity status, 50 (73\%) were scored as active lesions and 19 (27\%) as inactive lesions.

The Table 1 presents the results for sensitivity, specificity, area under the ROC curve, and interrater reliability regarding the ICDAS and Nyvad criteria used by students in two moments: when the students were just with theoretical knowledge about the criterion; and when they were with theoretical knowledge and clinical experience, after two years. These analyses were performed in order to clarify whether the students were able to base their treatment decisions on the different signs of carious lesions. The ICDAS criteria showed significant difference in sensitivity, specificity and AUC when the students were with theoretical knowledge compared to Nyvad criteria (McNemar's test, $\mathrm{P}<0.05$ ). However, after the students acquired theoretical knowledge and clinical experience, there was no difference in the performance of the two criteria. In fact, Nyvad criteria presented higher specificity and AUC values than did ICDAS criteria, but this difference was not significant.

Table 1. Sensitivity, specificity, area under the ROC curve (AUC), and interrater reliability shown by dental students.

\begin{tabular}{lcccccccc}
\hline \multirow{2}{*}{ Threshold* } & \multicolumn{2}{c}{ Sensitivity } & \multicolumn{2}{c}{ Specificity } & \multicolumn{2}{c}{ AUC } & \multicolumn{2}{c}{ Interrater } \\
\cline { 2 - 8 } & $\mathbf{T}$ & TC & T & TC & T & TC & T & TC \\
\hline \multirow{2}{*}{ ICDAS } & $0.82^{\mathrm{a} A \mathrm{~A}}$ & $0.94^{\mathrm{a}, \mathrm{A}}$ & $0.79^{\mathrm{a}, \mathrm{A}}$ & $0.93^{\mathrm{a}, \mathrm{A}}$ & $0.80^{\mathrm{a}, \mathrm{A}}$ & $0.85^{\mathrm{a}, \mathrm{A}}$ & 0.65 & 0.82 \\
& $(0.79-0.84)$ & $(0.89-0.99)$ & $(0.74-0.83)$ & $(0.88-0.98)$ & $(0.75-0.84)$ & $(0.79-0.89)$ & $(0.57-0.74)$ & $(0.78-0.93)$ \\
\hline \multirow{2}{*}{ Nyvad } & $0.50^{\mathrm{a}, \mathrm{B}}$ & $0.85^{\mathrm{b}, \mathrm{A}}$ & $0.65^{\mathrm{a}, \mathrm{B}}$ & $0.97^{\mathrm{b}, \mathrm{A}}$ & $0.58^{\mathrm{a}, \mathrm{B}}$ & $0.91^{\mathrm{b}, \mathrm{A}}$ & 0.41 & 0.81 \\
& $(0.42-0.61)$ & $(0.82-0.87)$ & $(0.57-0.77)$ & $(0.95-0.99)$ & $(0.52-0.60)$ & $(0.90-0.94)$ & $(0.34-0.47)$ & $(0.77-0.86)$ \\
\hline
\end{tabular}

Assessment: $\mathbf{N}$ - no knowledge about dental caries; $\mathbf{T}$ - theoretical knowledge; and TC - theoretical and clinical knowledge, after two years.

ICDAS: Sound and enamel lesions = 0-3, Dentin lesion = 4-6. Nyvad: Sound and inactive lesions = 0, 4-6, Active lesions $=1-3$.

a,b Difference between groups for the same criteria; A,B Difference between groups for different criteria (McNemar's test, $\mathrm{P}<0.05)$.

Regarding treatment decisions, Table 2 presents the percentages for the different treatments suggested for each criterion score and also the correlation between students and the reference standard. The first assessment performed by the students 
when they were in the second year of dental school, without any training or calibration about dental caries or support for criteria-based evaluations, showed the lowest correlation with the reference standard for both ICDAS $\left(r_{s}=0.43\right)$ and Nyvad $\left(r_{s}=0.40\right)$. For ICDAS criteria, operative treatment of initial lesions exhibited a high percentage (Score 1 = 73\%; Score 2 = 49\%; and Score $3=76 \%$ ), whereas non-operative treatments showed a lower percentage (Score $1=4 \%$; Score $2=44 \%$; and Score $3=11 \%$ ). Using Nyvad criteria, the students recommended non-operative treatments for inactive lesions (Score $4=37 \%$; Score $5=43 \%$ ) and non-treatment of active lesions (Score 1 = 47\%; Score 2 = 55\%).

The second assessment, the students were just with theoretical knowledge about the criterion. When they were introduced to the criteria and went through the training process, the correlation with the reference standard showed a considerable leap of improvement both for ICDAS $\left(r_{s}=0.75\right)$ and for Nyvad $\left(r_{s}=0.64\right)$. For ICDAS criteria, the second assessment revealed operative treatments were indicated less frequently for initial lesions (Score $1=0$; Score $2=3 \%$; and Score $3=57 \%$ ) and showed non-operative treatments were highly recommended for the same lesions (Score 1 = 64\%; Score 2 = 73\%; and Score 3 = 43\%). Nonetheless, despite improved consensus after the introduction of Nyvad criteria, preventive treatments continued to be recommended for inactive lesions (Score $4=61 \%$; Score $5=73 \%$ ).

The third assessment was performed after two years, when the students were with theoretical knowledge and clinical experience about criteria and dental caries. This experience, combined with the repeated training process, might explain the good correlation values obtained by both criteria (ICDAS $=0.89$; Nyvad $=0.87$ ). In addition, treatment decisions also presented greater cohesion in relation to the assigned classification criterion. For example, most of the students in the ICDAS group recommended preventive treatment for scores 1 (80\%) and 2 (100\%) and none of the students in the Nyvad group assigned preventive treatments for any lesion classified as inactive.

Table 2. Percentages of treatment decisions according to ICDAS and Nyvad criteria used by dental students in three assessments.

\begin{tabular}{|c|c|c|c|c|c|c|c|c|c|c|}
\hline \multirow{2}{*}{ Criterion } & \multirow{2}{*}{ Assessment* } & \multirow{2}{*}{$T D^{\star \star}$} & \multicolumn{7}{|c|}{ Criteria score } & \multirow{2}{*}{$r_{s}^{* * *}$} \\
\hline & & & 0 & 1 & 2 & 3 & 4 & 5 & 6 & \\
\hline \multirow[t]{9}{*}{ ICDAS } & $\mathrm{N}$ & 0 & 99 & 23 & 7 & 13 & 9 & 4 & & \\
\hline & & 1 & 1 & 4 & 44 & 11 & 11 & & & 0.43 \\
\hline & & 2 & & 73 & 49 & 76 & 80 & 96 & 100 & \\
\hline & $\mathrm{T}$ & 0 & 93 & 36 & 24 & & & & & \\
\hline & & 1 & 7 & 64 & 73 & 43 & 11 & 1 & & 0.75 \\
\hline & & 2 & & & 3 & 57 & 89 & 99 & 100 & \\
\hline & TC & 0 & 100 & 16 & & 6 & & & & \\
\hline & & 1 & & 80 & 100 & 22 & 29 & 2 & & 0.89 \\
\hline & & 2 & & 4 & & 72 & 71 & 98 & 100 & \\
\hline
\end{tabular}




\begin{tabular}{|c|c|c|c|c|c|c|c|c|c|c|}
\hline Nyvad & $\mathrm{N}$ & 0 & 100 & 47 & 55 & 2 & 42 & 8 & 2 & \multirow{3}{*}{0.40} \\
\hline & & 1 & & 31 & 37 & 4 & 37 & 43 & 13 & \\
\hline & & 2 & & 22 & 8 & 94 & 21 & 49 & 85 & \\
\hline & \multirow[t]{3}{*}{$\mathrm{T}$} & 0 & 100 & 25 & & & 31 & 1 & 5 & \multirow{3}{*}{0.64} \\
\hline & & 1 & & 70 & 39 & 17 & 61 & 73 & 25 & \\
\hline & & 2 & & 5 & 61 & 83 & 8 & 26 & 70 & \\
\hline & \multirow[t]{3}{*}{$\mathrm{TC}$} & 0 & 100 & & 8 & & 80 & 45 & 56 & \multirow{3}{*}{0.87} \\
\hline & & 1 & & 48 & 48 & 18 & & & & \\
\hline & & 2 & & 52 & 44 & 82 & 20 & 55 & 44 & \\
\hline
\end{tabular}

* Assessment: $\mathbf{N}$ - no knowledge about dental caries; $\mathbf{T}$ - theoretical knowledge; and TC - theoretical and clinical knowledge, after two years.

** TD (Treatment decision) - 0: no treatment; 1: non-operative treatment: oral hygiene instruction and application of $5 \%$ fluoride varnish; 2 : operative treatment: sealant or restoration with composite resin or restoration with conventional glass ionomer cement.

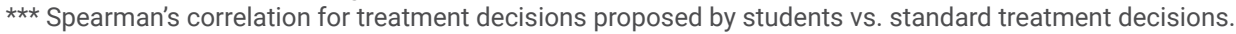

\section{Discussion}

In an attempt to investigate dental caries diagnosis and treatment decisions made by undergraduate students, this study used a longitudinal methodology to cover three different moments that could influence our results. Such influence may be related to the students' experience measured by caries diagnosis and treatment decision using ICDAS and Nyvad's system. Photographs were used to depict clinical situations ${ }^{20,21}$ that allowed reproducing the same lesions in the two-year period that involved this study, which would not have been possible in a clinical study. The use of extracted teeth is more common in studies that evaluate visual diagnostic criteria performance, enabling the study of reproducibility and avoiding patient exposure to multiple examinations ${ }^{14,20,21}$. However, this study protocol is not ideal for the evaluation of diagnostic criteria involving lesion activity signs, since extracted teeth do not allow visualization of indicators such as plaque stagnation area, roughness, quality of the marginal gingiva and lesions, translucency, or opacity. Moreover, the pre-specified surface to be evaluated also does not represent the clinical setting, where patient should be considered individually and the decisions should not be based specifically on a tooth 22 .

The increase in the correlation coefficient between undergraduate students and the gold standard regarding criteria-based treatment decisions suggests that the knowledge obtained during undergraduate years may improve the caries decision-making process, as suggested by some authors ${ }^{4,5,14}$. However, Foley ${ }^{23}$ did not observe improvement in the diagnosis of caries among students in the $2^{\text {nd }}, 3^{\text {rd }}$, and $4^{\text {th }}$ undergraduate years when criteria were used as an auxiliary tool. The differences in curricular components among undergraduate courses at different universities may affect the clinical approach of professionals in training ${ }^{4}$, and we believe these curricular disparities might explain the differences observed between our results and those obtained by the authors mentioned above. 
The visual examination commonly used for carious lesions detection in clinical practice has resulted in a lack of consensus on the proposed treatments because of subjective interpretation by the examiner ${ }^{5,24}$. Regarding the first evaluation based on ICDAS criteria, operative treatments were highly recommended for initial lesions, defined as "first visual changes in enamel" (Score 1), "distinct visual changes in enamel" (Score 2), and "localized enamel breakdown in opaque or discolored enamel" (Score 3), indicating that the proposed treatments were not compatible with the visual diagnosis, which could be due to lack of knowledge about the pathogenesis and management of dental caries. Bussaneli et al. ${ }^{16}$ also observed this more invasive pattern for initial lesions when the examiner had limited clinical experience; however, those studies evaluated treatment decisions when radiographic examination supported the visual examination. In our study, after the introduction of ICDAS criteria to the students and the training process, treatment decisions were less invasive for this same type of carious lesions. According to the literature, visual-tactile diagnostic systems can minimize subjective interpretation and can help the understanding and recognition of different caries signs by dental students ${ }^{14}$.

The correct recommendation of preventive and minimally invasive treatments ${ }^{23}$ may be better understood when considering the activity status of carious lesions because while active lesions need preventive measures for their inactivation, preventive treatment is dispensable ${ }^{13}$ for inactive lesions. Regarding the first assessment made by undergraduate students using Nyvad criteria, inactive lesions, presenting spots to large cavities (Scores 4-6), received a high percentage of preventive treatments, and active lesions, especially with "intact surface" (Score 1) and lesions with "surface discontinuity" (Score 2) received a high percentage of non-treatment decisions. After the introduction of Nyvad criteria and the training process, the recommendation of these treatments showed an inconsistent pattern. When evaluating criteria for the activity of carious lesions, Parviainen et al. ${ }^{18}$ and Gimenez et al. ${ }^{11}$ showed that undergraduate students were able to classify the signs of lesion activity when they had clinical/theoretical experience in cariology. We also observed a better application of Nyvad criteria by undergraduate students two years after the first assessment, when they had already had some clinical experience. After some clinical experience, treatment decisions showed correct indications of preventive treatments for lesions classified as active and of non-treatment for lesions classified as inactive.

For both ICDAS and Nyvad criteria, most lesions with dentin involvement received indications for operative treatment, whereas those classified as sound lesions received indication of treatment in both assessments. The correct identification of sound surfaces is extremely important to avoid false-positive results that may lead to unnecessary interventions ${ }^{25}$. The literature considers the indication of operative treatment as appropriate for dentin lesions, mainly because the procedure should be limited to lesions with signs of activity and proven demineralization on the tooth surface ${ }^{26}$.

Among the limitations of this study, convenience sampling might have limited the extrapolation of our results. A more or less interventional approach may affect treatment decisions established by the reference standard. In this way, we believe discussing the conciseness of the treatments in relation to the proposed classification and the improvement of knowledge throughout the course would be more important than 
the correlation between the groups and the reference standard. We also understand that visualization of lesion activity signs in photographs can be difficult and that the lack of tactile perception, with probing of the classified sites. Besides that, the fact that the criteria for the diagnosis of caries (ICDAS and Nyvad's) were used by different examiners is also a limitation of our study. We suggest that future studies assess other teaching-learning methods/tools for caries detection as expository lectures might not have been very significant for dental education.

Overall, the educational system does not focus on evaluating knowledge to determine the quality of student learning 27,28 . The learning score is a complex process because it encompasses factors that may not be measured in specific assessments; hence, the learning curve and academic experiences, either theoretical or practical, are just some aspects to be considered ${ }^{28}$.

In conclusion, our results showed that clinical experience could improve the detection of carious lesion and treatment decisions, regardless of the criteria used (ICDAS or Nyvad). These results are important to guide learning strategies in cariology, providing theoretical training and emphasizing the importance of clinical experience.

\section{Conflicts of interest:}

none.

\section{ACKNOWLEDGMENTS}

This study was financed in part by the Coordenação de Aperfeiçoamento de Pessoal de Nível Superior - Brazil (CAPES) - Finance Code 001.

\section{REFERENCES}

1. Maupomé G, Schrader S, Mannan S, Garetto L, Eggertsson H. Diagnostic thinking and information used in clinical decision-making: a qualitative study of expert and student dental clinicians. BMC Oral Health. 2010 May 13;10:11. doi: 10.1186/1472-6831-10-11.

2. Braga MM, Martignon S, Ekstrand KR, Ricketts DNJ, Imparato JCP, Mendes FM. Parameters associated with active caries lesions assessed by two different visual scoring systems on occlusal surfaces of primary molars-a multilevel approach. Community Dent Oral Epidemiol. 2010 Dec;38(6):549-58. doi: 10.1111/j.1600-0528.2010.00567.x.

3. Thammasitboon S, Cutrer WB. Diagnostic decision-making and strategies to improve diagnosis. Curr Probl Pediatr Adolesc Health Care. 2013 Oct;43(9):232-41. doi: 10.1016/j.cppeds.2013.07.003.

4. Bottenberg P, Ricketts DNJ, van Loveren C, Rahiotis C, Schulte AG. Decision-making and preventive non-surgical therapy in the context of a European Core Curriculum in Cariology. Eur J Dent Educ. 2011 Nov; 15 Suppl 1:32-9. doi: 10.1111/j.1600-0579.2011.00712.x.

5. Zandona AGF, Al-Shiha S, Eggertsson H, Eckert G. Student versus faculty performance using a new visual criteria for the detection of caries on occlusal surfaces: An in vitro examination with histological validation. Oper Dent. 2009;34(5):598-604. doi: 10.2341/08-082-L.

6. El-Damanhoury HM, Fakhruddin KS, Awad MA. Effectiveness of teaching international caries detection and assessment system II and its e-learning program to freshman dental students on occlusal caries detection. Eur J Dent. 2014 Oct;8(4):493-7. doi: 10.4103/1305-7456.143631. 
7. Ferreira-Nóbilo NP, de Sousa M da LR, Cury JA. Cariology in curriculum of Brazilian dental schools. Braz Dent J. 2014;25(4):265-70. doi: 10.1590/0103-6440201300149.

8. Turchiello RZ, Pedrotti D, Braga MM, Rocha RO, Rodrigues JA, Lenzi TL. Do undergraduate dental students perform well detecting and staging caries and assessing activity by visual examination? A systematic review and meta-analysis. Int J Paediatr Dent. 2019 May;29(3):281-93. doi: 10.1111/ipd.12463.

9. Zain E, Chew HP. Update on Clinical Detection Methods for Noncavitated Fissure Caries. World J Dent. 2020 Feb;11(1):81-8. doi: 10.5005/jp-journals-10015-1687

10. Ai I, Sohn W, Tellez M, Amaya A, Sen A, Hasson H, et al. The International Caries Detection and Assessment System (ICDAS): an integrated system for measuring dental caries. Comunity Dent Oral Epidemiol. 2007 Jun;35(3):170-8. doi: 10.1111/j.1600-0528.2007.00347.x.

11. Gimenez T, Piovesan C, Braga MM, Raggio DP, Deery C, Ricketts DN, et al. Visual inspection for caries detection: A systematic review and meta-analysis. J Dent Res. 2015 Jul;94(7):895-904. doi: 10.1177/0022034515586763.

12. Diniz MB, Campos PH, Wilde S, Cordeiro RCL, Zandona AGF. Performance of light-emitting diode device in detecting occlusal caries in the primary molars. Lasers Med Sci. 2019 Aug;34(6):1235-41. doi: 10.1007/s10103-019-02717-4

13. Nyvad B, Machiulskiene V, Baelum V. Reliability of a new caries diagnostic system differentiating between active and inactive caries lesions. Caries Res. 1999 Jul-Aug;33(4):252-60. doi: 10.1159/000016526.

14. Nogueira VKC, Bussaneli DG, Tagliaferro EPS, Spin-Neto R, Escobar A, Cordeiro RDCL. Examiner's experience and the outcome interpretation of ICDAS and Nyvad's system-a prospective in vitro study. Acta Odontol Scand. 2017 Apr;75(3):186-90. doi: 10.1080/00016357.2016.1277260.

15. Nogueira VKC, Bussaneli DG, Restrepo MR, Spin-Neto R, dos Santos-Pinto LAM, Boldieri T, et al. Caries treatment decisions among undergraduate and postgraduate students supported by visual detection systems. Int J Paediatr Dent. 2018 Jan;28(1):92-101. doi: 10.1111/ipd.12312.

16. Bussaneli DG, Boldieri T, Diniz MB, Lima Rivera LM, Santos-Pinto L, Cordeiro RCL. Influence of professional experience on detection and treatment decision of occlusal caries lesions in primary teeth. Int J Paediatr Dent. 2015 Nov;25(6):418-27. doi: 10.1111/ipd.12148.

17. Luz PB, Stringhini CH, Otto BR, Port ALF, Zaleski V, Oliveira RS, et al. Performance of undergraduate dental students on ICDAS clinical caries detection after different learning strategies. Eur J Dent Educ. 2015 Nov; 19(4):235-41. doi: 10.1111/eje.12131.

18. Parviainen $H$, Vähänikkilä $H$, Laitala $M L$, Tjäderhane $L$, Anttonen V. Evaluating performance of dental caries detection methods among third-year dental students. BMC Oral Health. 2013 Dec 6;13:70. doi: 10.1186/1472-6831-13-70.

19. Silva PF, Forte FDS, Chaves AMBP, Farias IAP, Castro KS. Reproducibility of caries diagnosis in permanent teeth according to WHO, ICDAS-II and Nyvad criteria. Brazilian J Oral Sci. 2012;11(1):25-9. doi: 10.20396/bjos.v1111.8641537

20. Heaven TJ, Gordan VV, Litaker MS, Fellows JL, Brad Rindal D, Firestone AR, et al. Agreement among dentists' restorative treatment planning thresholds for primary occlusal caries, primary proximal caries, and existing restorations: Findings from the National Dental Practice-Based Research Network. J Dent. 2013 Aug;41(8):718-25. doi: 10.1016/j.jdent.2013.05.014

21. Carvalho JC, Qvist V, Aimée NR, Mestrinho HD, Bakhshandeh A. Diagnosis, risk assessment, and treatment decisions for occlusal caries: A survey from the Danish Public Dental Health Service. Caries Res. 2018;52(1-2):58-70. doi: 10.1159/000484987. 
22. Uhlen MM, Valen H, Karlsen LS, Skaare AB, Bletsa A, Ansteinsson V, et al. Treatment decisions regarding caries and dental developmental defects in children - a questionnaire-based study among Norwegian dentists. BMC Oral Health. 2019 May;19(1):80. doi: 10.1186/s12903-019-0744-2.

23. Foley JI. Dental students consistency in applying the ICDAS system within paediatric dentistry. Eur Arch Paediatr Dent. 2012 Dec;13(6):319-22. doi: 10.1007/BF03320834.

24. Gordan V V., Bader JD, Garvan CW, Richman JS, Qvist V, Fellows JL, et al. Restorative treatment thresholds for occlusal primary caries among dentists in the Dental Practice-Based Research Network. J Am Dent Assoc [Internet]. 2010 Feb;141(2):171-84. doi: 10.14219/jada.archive.2010.0136.

25. Baelum V, Hintze H, Wenzel A, Danielsen B, Nyvad B. Implications of caries diagnostic strategies for clinical management decisions. Community Dent Oral Epidemiol. 2012 Jun;40(3):257-66. doi: 10.1111/j.1600-0528.2011.00655.x.

26. de Carvalho P, Bönecker M, Tello G, Abanto J, Oliveira LB, Braga MM. Inclusion of initial caries lesions in a population-based sample of Brazilian preschool children: Impact on estimates and treatment needs. PLoS One. 2020 Jun;15(6):e0234122. doi: 10.1371/journal.pone.0234122.

27. Hoffmann JML. [Metering assessment - a practice in construction from preschool to university]. Porto Alegre: Mediação; 2018. 192 p. Portuguese.

28. Luckesi CC. [Assessment of learning and ethics]. ABC Educ. 2006;7(54):20-1. Portuguese. 